INVITED REVIEW

\title{
Subclinical hyperthyroidism: clinical features and treatment options
}

\author{
Bernadette Biondi, Emiliano Antonio Palmieri ${ }^{1}$, Michele Klain ${ }^{2}$, Martin Schlumberger ${ }^{3}$, Sebastiano Filetti ${ }^{4}$ \\ and Gaetano Lombardi \\ Department of Clinical and Molecular Endocrinology and Oncology, University of Naples 'Federico II', Via S. Pansini 5, 80131 Naples, Italy. \\ ${ }^{1}$ Department of Clinical Medicine and Cardiovascular Sciences, University of Naples 'Federico II', Naples, Italy, ${ }^{2}$ Department of Bio-Morphological \\ and Functional Sciences, University of Naples 'Federico II', Naples, Italy, ${ }^{3}$ Nuclear Medicine Department, Institut Gustave Roussy, 94805 Villejuif, \\ France and ${ }^{4}$ Internal Medicine Department, University 'La Sapienza', Rome, Italy
}

(Correspondence should be addressed to B Biondi; Email: bebiondi@unina.it)

\begin{abstract}
Subclinical hyperthyroidism appears to be a common disorder. It may be caused by exogenous or endogenous factors: excessive TSH suppressive therapy with L-thyroxine (L-T4) for benign thyroid nodular disease, differentiated thyroid cancer, or hormone over-replacement in patients with hypothyroidism are the most frequent causes. Consistent evidence indicates that 'subclinical' hyperthyroidism reduces the quality of life, affecting both the psycho and somatic components of well-being, and produces relevant signs and symptoms of excessive thyroid hormone action, often mimicking adrenergic overactivity. Subclinical hyperthyroidism exerts many significant effects on the cardiovascular system; it is usually associated with a higher heart rate and a higher risk of supraventricular arrhythmias, and with an increased left ventricular mass, often accompanied by an impaired diastolic function and sometimes by a reduced systolic performance on effort and decreased exercise tolerance. It is well known that these abnormalities usually precede the onset of a more severe cardiovascular disease, thus potentially contributing to the increased cardiovascular morbidity and mortality observed in these patients. In addition, it is becoming increasingly apparent that subclinical hyperthyroidism may accelerate the development of osteoporosis and hence increased bone vulnerability to trauma, particularly in postmenopausal women with a pre-existing predisposition. Subclinical hyperthyroidism and its related clinical manifestations are reversible and may be prevented by timely treatment.
\end{abstract}

European Journal of Endocrinology 152 1-9

\section{Introduction}

Subclinical hyperthyroidism is characterized by a low or undetectable concentration of serum thyrotropin (TSH) with free tri-iodothyronine (FT3) and free thyroxine (FT4) levels within laboratory reference ranges. Although there is evidence that subclinical hyperthyroidism may have adverse tissue effects, the level of TSH suppression that determines these negative effects, and the management and treatment of this condition remain controversial issues $(1,2)$.

The definition of subclinical hyperthyroidism is based only on laboratory, not clinical, criteria and the term probably represents a misnomer (3). In fact, although in the normal reference range, serum thyroid hormones would be increased for the individual with low or undetectable serum TSH levels, thus determining a mild tissue hyperthyroidism. Indeed, the reference ranges for individual test results over a period of 12 months were more narrow than the group reference ranges on which laboratory reference ranges are based (4). Accordingly, conventional population-based reference intervals for thyroid function tests may not identify values that are outside the normal range for the individual being tested. The pituitary gland is sensitive to minor changes in serum thyroid hormone levels (5), and serum TSH responds with logarithmically amplified variations to such changes $(6,7)$. Therefore, the distinction between subclinical and overt hyperthyroidism, which is based on the populationbased reference range for thyroid hormone levels, is somewhat arbitrary and diagnosis depends on the position of the patient's set point for thyroid hormones within the laboratory reference range.

The view that individuals with an undetectable serum TSH level suffer from a mild form of tissue hyperthyroidism sensu strictu is supported by the finding of relevant changes in several cardiovascular measures and in bone structure and metabolism in these individuals. Importantly, these changes 
significantly impair quality of life and, especially in the elderly, greatly increase the risk of cardiovascular morbidity and mortality, and of bone fractures.

In this article we have reviewed the literature on subclinical hyperthyroidism, particularly as regards to its clinical features and treatment options. Our intention is to provide physicians with a tool to manage this condition according to the principles of evidence-based medicine.

\section{Etiology and differential diagnosis}

Subclinical hyperthyroidism may be caused by exogenous or endogenous factors (8), and may be transient or persistent (Table 1). Adverse tissue effects are similar, whatever the cause of subclinical hyperthyroidism and mainly depend on the duration of the disease. The exogenous form of subclinical hyperthyroidism is usually related to TSH-suppressive therapy with L-thyroxine (L-T4) for a single thyroid nodule, multinodular goiter, or differentiated thyroid carcinoma. In addition, TSH may be unintentionally suppressed during hormone replacement therapy in about $20 \%$ of hypothyroid patients $(9,10)$. The endogenous form is usually related to the same causes as overt thyrotoxicosis, namely Graves' disease, autonomously functioning thyroid adenoma, and multinodular goiter. The two latter causes are particularly frequent in the elderly, especially in areas of iodine deficiency (11-13).

It is important to recognize that subnormal levels of serum TSH do not always reflect the presence of subclinical hyperthyroidism. Subnormal serum TSH may occur in patients with pituitary or hypothalamic insufficiency, or non-thyroid pathological conditions, or consequent to administration of the glucocorticoids, dopamine or amiodarone (14). In addition, TSH concentration may be below the normal range in some elderly patients as a result of decreased age-related thyroid hormone clearance (15). In any case, a careful physical examination, a detailed medical history, and the pattern of thyroid hormones may help to diagnose these conditions.

\section{Epidemiology and natural history}

To date, there is no definitive information about the incidence of subclinical hyperthyroidism in the general population. Its prevalence ranges from 0.6 to $16 \%$ (10, 16-18) depending on diagnostic criteria, the sensitivity

Table 1 Causes of persistent subclinical hyperthyroidism.

\section{Endogenous causes}

Graves' disease

Autonomously functioning thyroid adenoma

Multinodular goiter

Exogenous causes

Excessive thyroid hormone replacement therapy

Intentional thyroid hormone suppressive therapy of the methods used to measure serum TSH concentrations, and iodine intake. Moreover, the reported prevalence of subclinical hyperthyroidism is affected by the investigator's definition of the lower limit of the normal range for TSH being $0.7 \%$ when the TSH cut-off point was $0.1 \mathrm{mU} / \mathrm{l}$ (19) and $2.1 \%$ with a TSH cut-off of $0.3 \mathrm{mU} / \mathrm{l}$ (10). In any event, subclinical hyperthyroidism appears to be a frequent disorder; TSH suppressive or unintentional over-replacement L-T4 therapy being the most common causes.

In patients with toxic adenoma or multinodular goiter, subclinical hyperthyroidism is usually a slowly progressive disorder and may last several years before being diagnosed. Factors that may precipitate overt hyperthyroidism are age, iodine prophylaxis in areas of endemic goiter (11), and administration of an iodide-containing contrast agent. Prospective studies of patients with endogenous subclinical hyperthyroidism show that TSH normalizes in almost $50 \%$ of cases, whereas overt hyperthyroidism develops at a rate of 5\% per year (20). A recent panel of experts (1) classified patients with subclinical hyperthyroidism into two categories: those with mildly low but still detectable serum TSH $(0.1-0.4 \mathrm{mU} / \mathrm{l})$ and those with an undetectable serum TSH level $(<0.1 \mathrm{mU} / \mathrm{l})$ (1). The progression to overt hyperthyroidism was less common in patients with low TSH than in patients with undetectable TSH (21).

\section{Clinical features}

\section{Signs, symptoms and quality of life}

With the exception of one study (22), subclinical hyperthyroidism is associated with relevant signs and symptoms of thyroid hormone excess, and with impaired quality of life $(12,22-29)$. With different kinds of questionnaires formulated to investigate the psychophysical effects of thyroid hormone, patients with subclinical hyperthyroidism, whether exogenous $(23-25)$ or endogenous $(26,27)$, were found to have a higher prevalence of palpitations, tremor, heat intolerance, sweating, nervousness, anxiety, reduced feeling of well-being, fear, hostility, and inability to concentrate. Noteworthy, in a retrospective study a near threefold increased risk of dementia and Alzheimer's disease was found in patients with subclinical hyperthyroidism (29).

\section{Cardiovascular system}

Thyroid hormone excess causes a wide spectrum of cardiovascular changes, which arise from both direct and indirect effects on the cardiovascular system, and effects mediated by neurohormonal activation (30-32). The cardiovascular risk of subclinical hyperthyroidism is related to short-term effects due to the electrophysiological effects of thyroid hormones, and to long-term 
effects resulting from increased left ventricular mass and increased cardiac workload (Table 2). In most studies, patients with subclinical hyperthyroidism, whether exogenous $(23-25,33-36)$ or endogenous $(26,27,37)$, have a higher heart rate and increased prevalence of supraventricular arrhythmias, as assessed by 24-h Holter electrocardiographic monitoring. In individuals with a shorter $\mathrm{P}-\mathrm{R}$ interval on standard electrocardiogram, due to the presence of two functionally distinct atrio-ventricular nodal pathways, subclinical hyperthyroidism may precipitate re-entrant atrio-ventricular nodal tachycardia (38).

In a longitudinal study over 2 years of atrial fibrillation conducted in 40 patients with subclinical hyperthyroidism (mean age 65 years), the total rate of atrial fibrillation was $28 \%$ in patients with endogenous subclinical hyperthyroidism (serum TSH $<0.1 \mathrm{mU} / \mathrm{l})$, compared with $10 \%$ in age-matched euthyroid controls (39).

Importantly, data from a 10-year follow-up study of elderly patients with endogenous or exogenous subclinical hyperthyroidism (serum $\mathrm{TSH} \leq 0.1 \mathrm{mU} / \mathrm{l}$ ) indicate that this disorder is associated with a threefold higher incidence of atrial fibrillation compared with euthyroid healthy subjects (40).

Similarly, in a retrospective study of 1338 consecutive subjects with endogenous subclinical hyperthyroidism, the prevalence of atrial fibrillation was increased to a similar degree in older people with overt and subclinical hyperthyroidism (41): $2.3 \%$ in euthyroid subjects (TSH $>0.4-5 \mathrm{mU} / \mathrm{l}), 13.8 \%$ in patients with overt hyperthyroidism $(\mathrm{TSH} \leq 0.03 \mathrm{mU} / \mathrm{l}$ with elevated FT3 and FT4), and $12.7 \%$ in patients with subclinical hyperthyroidism $(\mathrm{TSH}<0.4-0.03 \mathrm{mU} / \mathrm{l})$. The relative risk of atrial fibrillation was 5.8 and 5.2 respectively compared with euthyroid subjects $(P<0.01)(41)$.

Moreover, subclinical hyperthyroidism was found to be an independent risk factor for atrial fibrillation in patients with other pre-existing cardiac risk factors (e.g. coronary heart disease, valvular defects, hypertension) (42).

In this context, the adverse arrhythmogenic effects associated with subclinical hyperthyroidism, most probably triggered by the enhancement of atrial excitability and the shortening of the refractory period of

Table 2 Cardiovascular risk in patients with subclinical hyperthyroidism.

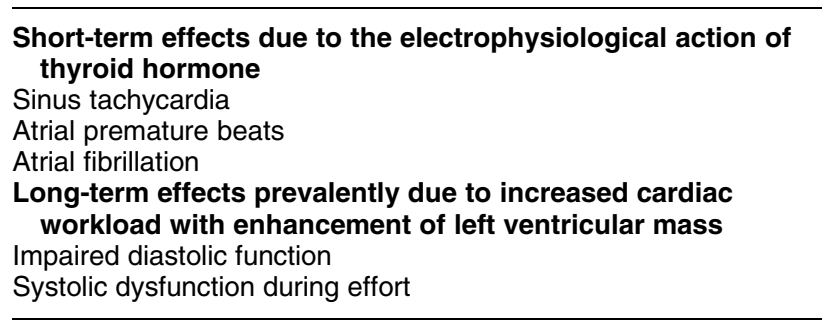

the conducting tissue, may be particularly hazardous in the elderly, whose cardiovascular function is often borderline. Indeed, atrial fibrillation by itself is an independent risk factor for stroke, angina pectoris, and congestive heart failure, and is associated with a twofold higher risk of death $(43,44)$.

The most consistent cardiac abnormality reported in patients with exogenous $(23-25,35,36,45-48)$ and endogenous $(26,27)$ subclinical hyperthyroidism, regardless of the underlying etiology, is a significant increase in left ventricular mass $(23-27,35,36,45)$, with unchanged or increased at-rest systolic function (23-27, 35-36, 46-48), and usually impaired diastolic function that is mainly due to slowed ventricular relaxation $(25-27,36,45,49)$. Using Doppler echocardiography in 60 patients with exogenous subclinical hyperthyroidism, it was found that the left ventricular mass index and various indices of resting left ventricular systolic function were significantly increased compared with euthyroid healthy controls, whereas diastolic function was impaired as documented by the reduced ratio between early and late diastolic peak flow velocities and the prolonged isovolumic relaxation time (36).

The cardiovascular abnormalities were similar in patients with either stable endogenous subclinical hyperthyroidism or exogenous hyperthyroidism (26, 27). Indeed, only one study did not find cardiac abnormalities in patients with endogenous subclinical hyperthyroidism (50).

The mechanism responsible for the increased left ventricular mass and diastolic dysfunction in both exogenous and endogenous subclinical hyperthyroidism is unclear. Cardiac hypertrophy and diastolic dysfunction are hallmarks of chronic hemodynamic overload, arising from relevant molecular rearrangements within the heart, including increased synthesis of contractile proteins and decreased activity of the sarcoplasmic reticulum calcium ATPase. This latter mechanism, in particular, plays a key role in impairing the efficiency of calcium reuptake by the sarcoplasmic reticulum during diastole, and hence in slowing the rate of relaxation of hypertrophied myocardium. However, the operation of these mechanisms in subclinical hyperthyroidism conflicts with the well-known favorable effects promoted by thyroid hormone on intracellular calcium handling, mostly due to the increased activity of the sarcoplasmic reticulum calcium ATPase (31). It may be speculated that, in the long-term, the negative effects promoted by the chronically increased cardiac workload on sarcoplasmic reticulum calcium ATPase overwhelm the positive effects promoted by thyroid hormone, thus leading to impaired myocardial relaxation and diastolic dysfunction $(49,51,52)$.

Functional implications of these cardiac abnormalities were shown in patients with exogenous subclinical hyperthyroidism. Using the bicycle ergometer test, significant reductions in the peak workload and exercise 
duration were found, and were associated with left ventricular systolic dysfunction on effort, as indicated by the poor increase $(\leq 5 \%)$ or even a decreased ejection fraction during exercise (53). Similarly, using cardiopulmonary exercise testing, exercise tolerance and oxygen uptake at peak exercise and at the anaerobic threshold were significantly decreased (25).

Unfortunately a stratified analyses of TSH value (low or undetectable) was not performed in the studies evaluating the cardiovascular effects of exogenous or endogenous subclinical hyperthyroidism, with the exception of the above-mentioned studies on atrial fibrillation (39-41). However, cardiovascular mortality was found to be increased in a community-based review of subjects aged 60 years or older with endogenous subclinical hyperthyroidism (with TSH values $<0.5 \mathrm{mU} / \mathrm{l}$ ) monitored for 10 years (54). All the above-mentioned cardiac abnormalities might play a role in determining the increased cardiovascular mortality and morbidity in elderly patients with subclinical hyperthyroidism (55).

\section{Bone structure and metabolism}

Overt hyperthyroidism is an important risk factor for osteoporosis and fractures (56-59). Thyroid hormones accelerate the rate of bone remodeling, leading to a negative calcium balance and a net bone loss that accelerates the development of osteoporosis, and hence increases bone vulnerability to trauma (5860). Whether subclinical hyperthyroidism significantly affects bone metabolism and increases the risk of fractures remains a controversial issue. Serum concentrations of several markers of bone synthesis and reabsorption, i.e. osteocalcin and telopeptide type I, and urinary pyridinoline crosslinks and hydroxyproline, are increased in patients with subclinical hyperthyroidism (61-65) and negatively correlated to serum TSH concentrations (62). In several cross-sectional studies, bone mineral density was decreased at multiple sites in pre- (66-69) and postmenopausal women $(69-74)$ with exogenous $(66-69,72)$ or endogenous $(68,73-74)$ subclinical hyperthyroidism. This finding, however, was not confirmed in other cross-sectional observations in pre- $(70,75-86)$ and postmenopausal conditions $(76,79-82,84,87-91)$, and in exogenous $(76,77-83,85-90)$ and endogenous conditions $(75,84)$. Similar results were found in longitudinal studies with decreased or normal bone mineral density in pre- (92-94) or postmenopausal women $(72,91,92-95)$ with exogenous subclinical hyperthyroidism. Indeed, in two meta-analyses, exogenous subclinical hyperthyroidism was associated with a significant bone loss in post- but not in premenopausal women $(96,97)$.

There are at least five explanations for these discrepancies between studies. First, during the last two decades the doses of L-T4 used to suppress TSH in patients with benign thyroid disease have been progressively reduced. This observation may account for the conflicting results among the early and the more recent studies; it also suggests that careful adjustment of L-T4 therapy can minimize the risk of bone loss, providing de facto indirect evidence for the association between subclinical hyperthyroidism and the development and progression of osteoporosis. Secondly, criteria for patient inclusion in these studies have become more restrictive. In fact, many early studies included patients with previous overt hypo- or hyperthyroidism. Thirdly, because the extent of bone loss depends on the magnitude of thyroid hormone excess and its duration, differences in follow-up among longitudinal studies may have contributed to conflicting results. Fourthly, discrepancies among studies exist in the methodology and the protocol used to measure bone mineral density and accurate techniques were applied only recently. Finally, other risk factors for bone loss may have interfered with thyroid hormone excess, accelerating the development of osteoporosis in some cases and attenuating it in others. These include a relative deficiency of calcitonin, insulin-like growth factor type I, dehydroepiandrosterone sulfate, and estrogen $(71,98-100)$.

In conclusion, subclinical hyperthyroidism predominantly depletes skeletal sites that are rich in cortical bone, depending mainly on disease severity and duration, and the association with other risk factors for bone loss.

The question as to whether subclinical hyperthyroidism increases the risk of fractures also remains controversial. In a study based upon interviews of 300 white postmenopausal women, no increased fracture risk was found in women taking L-T4 (101). In a study of 1180 patients treated with L-T4, the overall fracture rate in women over 65 years after 5 years was $2.5 \%$ in those with low TSH, and $0.9 \%$ in those with normal TSH values; the difference was not statistically significant (102).

A population-based, case-controlled analysis in a large cohort of patients from the UK found no association between the risk of femur fracture and treatment with L-T4 (103); however, after correction for other confounding risk factors, the risk of femur fracture was significantly associated with L-T4 therapy in males. In a prospective cohort study with case-cohort sampling on 686 women older than 65 years of age with low serum TSH (104), the risk of fractures was studied after adjusting for age, history of previous hyperthyroidism, and use of estrogen and thyroid hormone treatment; women with TSH levels $<0.1 \mathrm{mU} / \mathrm{l}$ had a threefold increased risk for hip fracture and a fourfold increased risk for vertebral fracture compared with women with a normal TSH concentration. In any event, the use of thyroid hormone by itself does not appear to increase the risk for fracture if TSH levels are maintained within the normal range. 


\section{Treatment options}

\section{Symptoms, signs and quality of life}

Administration of the cardioselective $\beta$-blocker bisoprolol for 6 months significantly improves the mean symptom rating scale score in patients with exogenous subclinical hyperthyroidism, mostly because this treatment attenuates many signs and symptoms mimicking adrenergic overactivity (23). Similar results were obtained with individual tailoring of the TSH-suppressive dose of L-T4, although the mean score remained significantly higher than that of euthyroid healthy controls (25). Moreover, treatment for 6 months with methimazole significantly improved symptoms evaluated with the Wayne index in endogenous subclinical hyperthyroid patients, paralleling the normalization of the thyroid status (27).

\section{Cardiovascular system}

In patients with exogenous subclinical hyperthyroidism, the addition of the cardioselective $\beta$-blocker bisoprolol to L-T4 therapy for 6 months significantly reduced the occurrence of supraventricular arrhythmias, average heart rate, and left ventricular mass, with improvement of diastolic function at rest and systolic performance during exercise $(23,53)$. Similarly, individual tailoring of the L-T4 dose in patients requiring TSH-suppressive treatment significantly decreased left ventricular mass and increased maximum workload (25). A decrease in the average 24-h heart rate, atrial premature beats, and left ventricular mass has also been reported in patients with endogenous subclinical hyperthyroidism after restoration of euthyroidism by methimazole treatment (27). Moreover, antithyroid therapy was beneficial in restoring a normal sinus rhythm in elderly patients affected by subclinical hyperthyroidism with atrial fibrillation (105). Recently, a study with impedance cardiography found that radioiodine treatment in women with endogenous subclinical hyperthyroidism significantly attenuated the pretreatment cardiac and hemodynamic abnormalities, as indicated by a reduction in heart rate, a normalized cardiac index, and an increased systemic vascular resistance (106). Importantly, patients with new onset of atrial fibrillation may have occult subclinical hyperthyroidism and the treatment with antithyroid drugs may reverse the atrial fibrillation in these cases. This supports the hypothesis that subclinical thyrotoxicosis is among the factors that trigger atrial fibrillation $(107,108)$.

\section{Bone and mineral metabolism}

Women affected by endogenous subclinical hyperthyroidism who were treated with antithyroid drugs for 2 years or with radioiodine significantly increased bone mineral density when compared with untreated women, in whom a progressive bone loss frequently occurs $(73,109)$.

In exogenous subclinical hyperthyroidism, the use of carefully tailored TSH-suppressive doses of L-T4 did not contribute to osteopenia $(78,95)$. Several studies have shown that the negative effects of thyroid hormone on bone can be obviated by adequate dietary calcium intake, bisphosphonates, or by estrogen replacement therapy in postmenopausal women $(71,110-112)$.

\section{Concluding remarks}

Three main conclusions may be drawn from the available data. The first is that subclinical hyperthyroidism is a very common disorder. Excessive TSH-suppressive therapy with L-T4 for benign thyroid nodular disease or differentiated thyroid cancer, or hormone over-replacement in patients with hypothyroidism are the most frequent causes. Nonetheless, endogenous factors are frequent in areas with endemic goiter and iodine prophylaxis, and particularly in elderly subjects. The second conclusion is that the adjective 'subclinical' is a misnomer for this disorder (3). In fact, 'subclinical' hyperthyroidism reduces the quality of life, affecting both the psycho and somatic components of wellbeing, and produces relevant signs and symptoms of excessive thyroid hormone action, often mimicking adrenergic overdrive. 'Subclinical' hyperthyroidism exerts many relevant effects on the cardiovascular system (113). It is usually associated with a higher heart rate and a higher risk of supraventricular arrhythmias, and with an increased left ventricular mass, often accompanied by impaired diastolic function and, sometimes, by reduced systolic performance on effort and decreased exercise tolerance. Indeed, these abnormalities usually precede the onset of more severe cardiovascular disease, thus potentially contributing to the increased risk for cardiovascular morbidity and mortality observed in these patients. In addition, 'subclinical' hyperthyroidism may accelerate the development of osteoporosis, and hence increase bone vulnerability to trauma, particularly in postmenopausal women with a pre-existing predisposition (Table 3). On this basis, the socio-economic burden of 'subclinical' hyperthyroidism may be greater than

Table 3 Potential skeletal effects of subclinical hyperthyroidism.

\section{Increased markers of bone turnover}

Reduced bone density in estrogen-deficient postmenopausal women

Increased risk of fracture in postmenopausal women

Subclinical hyperthyroidism predominantly depletes skeletal sites rich in cortical bone, mainly depending on the severity and duration of TSH suppression, and the association with other well-recognized risk factors for bone loss

The use of thyroid hormone by itself does not increase the risk of fracture if TSH levels are maintained within the normal range 
previously thought. The third conclusion is that "subclinical' hyperthyroidism and its related clinical manifestations are reversible or may be prevented by timely treatment. In patients treated for benign thyroid nodular disease, the dose of L-T4 should be carefully customized, keeping serum TSH near, but not below the lower limit of the normal reference range. In patients on hormone replacement therapy for hypothyroidism, periodic evaluations of serum TSH levels should ensure that replacement therapy is not under- or over-prescribed. In patients with differentiated thyroid cancer with a high risk of recurrences or with known metastatic disease, in whom long-term sustained TSH suppression is warranted, $\beta$-blockade and bone-sparing drugs may be considered, in particular in patients above the age of 45 years, since they blunt or even prevent cardiovascular manifestations, and reduce the risk for osteoporosis and bone fractures. This concerns only a small minority of patients. In fact, in low-risk patients with differentiated thyroid cancer, the aim of L-T4 treatment is to maintain serum TSH levels within the normal reference range, once the absence of persistent disease has been documented.

Finally, in patients with endogenous 'subclinical' hyperthyroidism whatever the cause, especially in elderly patients, the treatment strategy should be the same as that for overt disease, i.e. methimazole administration for a rapid control of thyroid hormone excess, and radioiodine or surgery for a definitive cure, both eventually associated with a $\beta$-blocking drug.

A recent panel of experts recommends that the treatment of endogenous subclinical hyperthyroidism should be considered in the presence of TSH $<0.1 \mathrm{mU} / \mathrm{l}$ especially for patients who are older than 60 years and for those with an increased risk for heart disease, osteopenia or osteoporosis, or for those with clinical symptoms suggestive of hyperthyroidism (1). The routine treatment is not recommended for all patients whose TSH is mildly decreased (0.1$0.45 \mathrm{mU} / \mathrm{l})$ (1). In fact, it remains to be established whether a low serum TSH level may be associated with the same adverse effects on bone and heart as an undetectable TSH level $(1,2)$. In this context, the extent of clinical manifestations of 'subclinical' hyperthyroidism is probably related not only to the magnitude of thyroid hormone excess but also to disease duration, individual sensitivity to thyroid hormone excess, and particularly to the patient's age.

Although almost clinical manifestations of 'subclinical' hyperthyroidism have been described in patients with long-term treatment or persistent disease, transient suppression of serum TSH, as may occur in the course of many thyroid diseases or during L-T4 up-titration, may precipitate such cardiovascular signs and symptoms as palpitations and supraventricular arrhythmias. In the elderly, the symptoms and signs of hyperthyroidism may be unnoticed even in the presence of overt disease (114), with atrial fibrillations being the usual clinical presentation (115). Therefore, 'subclinical' hyperthyroidism should always be considered as a possible cause of recent onset supraventricular arrhythmias, particularly in the elderly, and thus be treated in a timely fashion with a $\beta$-blocking drug.

\section{References}

1 Surks MI, Ortiz E, Daniels GH, Sawin CT, Col NF, Cobin RH, Franklyn JA, Burman KD, Denke MA, Cooper RS \& Weissman NJ. Subclinical thyroid disease. Scientific review and guidelines for diagnosis and management. Journal of the American Medical Association $2004291228-238$.

2 McDermott MT, Woodmansee WW, Haugen BR, Smart A \& Ridgway EC. The management of subclinical hyperthyroidism by thyroid specialists. Thyroid 200313 1133-1139.

3 Ladenson PW. Thyrotoxicosis and the heart: something old and something new. Journal of Clinical Endocrinology and Metabolism $199377332-333$.

4 Andersen S, Pedersen KM, Brunn NH \& Laurberg P. Narrow individual variations in serum $\mathrm{T} 4$ and $\mathrm{T} 3$ in normal subjects: a clue to understanding of subclinical thyroid disease. Journal of Clinical Endocrinology and Metabolism 200287 1068-1072.

5 Carr D, McLeod DT, Parry G \& Thornes HM. Fine adjustment of thyroxine replacement dosage: comparison of the thyrotropin releasing hormone test using sensitive thyrotropin assay with measurement of free thyroid hormone and clinical assessment. Clinical Endocrinology 198828 325-333.

6 Spencer CA, Lopresti JS, Patel A, Guttler RB, Eigen A, Shen D, Gray D \& Nicoloff JT. Applications of a new chemiluminescent thyrotropin assay to subnormal measurement. Journal of Clinical Endocrinology and Metabolism 1990 70 453-460.

7 Meier CA, Maisen MN, Lowry A, Müller J \& Smith MA. Interindividual differences in the pituitary-thyroid axis influence the interpretation of thyroid function tests. Clinical Endocrinology $199339101-107$.

8 Ross DS. Subclinical thyrotoxicosis. In Werner and Ingbar's The Thyroid: A Fundamental and Clinical Text, pp 1016-1020, edn 8. Eds LE Braverman \& RD Utiger. Philadelphia: Lippincott Williams and Wilkins, 2000.

9 de Whalley P. Do abnormal thyroid stimulating hormone level values result in treatment changes? A study of patients on thyroxine in one general practice. British Journal of General Practice $19954593-95$.

10 Canaris GJ, Manovitz NR, Mayor G \& Ridgway EC. The Colorado thyroid disease prevalence study. Archives of Internal Medicine $2000160526-534$

11 Belfiore A, Sava L, Runello F, Tomaselli L \& Vigneri R. Solitary autonomously functioning thyroid nodules and iodine deficiency. Journal of Clinical Endocrinology and Metabolism $1996 \mathbf{5 6}$ 283-287.

12 Stott DJ, McLellan AR, Finlayson J, Chu P \& Alexander WD. Elderly patients with suppressed serum TSH but normal free thyroid hormone levels usually have mild thyroid overactivity and are at risk of developing overt hyperthyroidism. Quarterly Journal of Medicine 199178 77-84.

13 Aghini-Lombardi F, Antonangeli L, Martino E, Vitti P, Maccherini D, Leoli F, Rago T, Grasso L, Valeriano R, Balestrieri A \& Pinchera A. The spectrum of thyroid disease in an iodinedeficient community: the Pescopagano survey. Journal of Clinical Endocrinology and Metabolism $199984561-566$.

14 Spencer C, Eigen A, Shen D, Duda M, Qualls S, Weiss S \& Nicoloff J. Specificity of sensitive assay of thyrotropin (TSH) used to screen for thyroid disease in hospitalized patients. Clinical Chemistry 198733 1391-1396.

15 Drinka PJ. Abnormal TSH: a rational approach to the older patient. Geriatrics $19995 \mathbf{5 4} 58-65$. 
16 Marqusee E, Haden ST \& Utiger RD. Subclinical thyrotoxicosis. Endocrinology and Metabolism Clinics of North America 199827 37-49.

17 Wang C \& Crapo LM. The epidemiology of thyroid diseases and implications for screening. Endocrinology and Metabolism Clinics of North America 197726 189-218.

18 Samuels MH. Subclinical thyroid disease in the elderly. Thyroid 19988 803-813.

19 Hollowell JG, Staehling NW, Flanders WD, Hannon WH, Gunter EW, Spencer CA \& Braverman LE. Serum TSH T(4), and thyroid antibodies in the United States population (19881994): National Health and Nutrition Examination Survey (NHANESIII). Journal of Clinical Endocrinology and Metabolism $200287486-488$.

20 Wiersinga WM. Subclinical hyperthyroidism and hypothyroidism. Prevalence and clinical relevance. Netherlands Journal of Medicine 199546 197-204.

21 Parle JV, Franklyn JA, Cross KW, Jones SC \& Sheppard MC. Prevalence and follow-up of abnormal thyrotrophin (TSH) concentrations in the elderly in the United Kingdom. Clinical Endocrinology $19913477-83$.

22 Schlote B, Schaaf L, Schmidt R, Pohl T, Vardarli I, Schiebeler H, Zober MA \& Usadel KH. Mental and physical state in subclinical hyperthyroidism: investigations in a normal working population. Biological Psychiatry 199232 48-56.

23 Biondi B, Fazio S, Carella C, Sabatini D, Amato G, Cittadini A, Bellastella A, Lombardi G \& Sacca L. Control of adrenergic overactivity by $\beta$-blockade improves quality of life in patients receiving long term suppressive therapy with levothyroxine. Journal of Clinical Endocrinology and Metabolism $1994 \mathbf{7 8} 1028-1033$.

24 Shapiro LE, Sievert R, Ong L, Ocampo EL, Chance RA, Lee M, Nanna M, Ferrick K \& Surks MI. Minimal cardiac effects in asymptomatic athyreotic patients chronically treated with thyrotropin-suppressive doses of L-thyroxine. Journal of Clinical Endocrinology and Metabolism 199782 2592-2595.

25 Mercuro G, Panzuto MG, Bina A, Leo M, Cabura R, Petrini L, Pigliaru F \& Mariotti S. Cardiac function, physical exercise capacity, and quality of life during long-term thyrotropin-suppressive therapy with levothyroxine: effect of individual dose tailoring. Journal of Clinical Endocrinology and Metabolism 200085 159-164.

26 Biondi B, Palmieri EA, Fazio S, Cosco C, Nocera M, Saccà L, Filetti S, Lombardi G \& Perticone F. Endogenous subclinical hyperthyroidism affects quality of life and cardiac morphology and function in young and middle-aged patients. Journal of Clinical Endocrinology and Metabolism 200085 4701-4705.

27 Sgarbi JA, Villaca F, Garbeline B, Villar HE \& Romaldini JH. The effects of early antithyroid therapy for endogenous subclinical hyperthyroidism on clinical and heart abnormalities. Journal of Clinical Endocrinology and Metabolism 200388 1672-1677.

28 Bommer M, Eversmann T, Pickardt R, Leonhardt A \& Naber D. Psychopathological and neuropsychological symptoms in patients with subclinical and remitted hyperthyroidism. Klinische Wochenschrift $1990 \mathbf{6 8} 552-558$.

29 Kalmijn S, Mehta KM, Pols HA, Hofman A, Drexhage HA \& Breteler MM. Subclinical hyperthyroidism and the risk of dementia. The Rotterdam study. Clinical Endocrinology 200053 733-737.

30 Biondi B, Palmieri EA, Lombardi G \& Fazio S. Effects of thyroid hormone on cardiac function: the relative importance of heart rate, loading conditions, and myocardial contractility in the regulation of cardiac performance in human hyperthyroidism. Journal of Clinical Endocrinology and Metabolism $2002 \mathbf{8 7}$ 968-974.

31 Klein I \& Ojamaa K. Thyroid hormone and the cardiovascular system. New England Journal of Medicine $2001344501-509$.

32 Fazio S, Palmieri EA, Lombardi G \& Biondi B. Effects of thyroid hormone on the cardiovascular system. Recent Progress in Hormone Research 200459 31-50.
33 Bell GM, Sawers SA, Forfar JC, Doig A \& Toft D. The effect of minor increments in plasma thyroxine on heart rate and urinary sodium excretion. Clinical Endocrinolology $198318511-516$.

34 Grund FM \& Niewoehner CB. Hyperthyroidism in patients receiving thyroid replacement therapy. Archives of Internal Medicine $1989149921-929$.

35 Biondi B, Fazio S, Carella C, Amato G, Cittadini A, Lupoli G, Sacca L, Bellastella A \& Lombardi G. Cardiac effects of longterm thyrotropin-suppressive therapy with levothyroxine. Journal of Clinical Endocrinology and Metabolism 199377 334-338.

36 Biondi B, Fazio S, Palmieri EA, Tremalaterra R, Angellotti G, Bonè F, Riccio G, Cittadini A, Lombardi G \& Saccà L. Effects of chronic subclinical hyperthyroidism on cardiac morphology and function. Cardiologia 199944 443-449.

37 Boutin JM, Matte R, D'Amour P, Gilbert F, Havrankova J, Belanger R, Chartrand R \& Zakarija M. Characteristic of patients with normal $\mathrm{T}_{3}$ and $\mathrm{T}_{4}$ and low TSH response to TRH. Clinical Endocrinology 198625 579-588.

38 Biondi B, Fazio S, Coltorti F, Palmieri EA, Carella C, Lombardi G \& Saccà L. Clinical case seminar: Reentrant atrioventricular nodal tachycardia induced by levothyroxine. Journal of Clinical Endocrinology and Metabolism $1998 \mathbf{8 3} 2643-2645$.

39 Tenerz A, Forberg R \& Jansson R. Is a more active attitude warranted in patients with subclinical thyrotoxicosis? Journal of Internal Medicine 1999228 229-233.

40 Sawin CT, Geller A, Wolf PA, Belanger AJ, Baker E, Bacharach P, Wilson PW, Benjamin EJ \& D'Agostino RB. Low serum thyrotropin concentrations as a risk factor for atrial fibrillation in older persons. New England Journal of Medicine 1994331 1249-1252.

41 Auer JA, Scheibner P, Mische T, Langsteger W, Eber O \& Eber B. Subclinical hyperthyroidism as a risk factor for atrial fibrillation. American Heart Journal 2001142 838-842.

42 Hammer J, Johanningmann K, Schatz H \& Pfeilschifter J. Subclinical hyperthyroidism is an independent risk factor for atrial fibrillation in patients with preexisting cardiac disease. Experimental and Clinical Endocrinology and Diabetes 2001109 S37.

43 Benjamin EJ, Wolf PA, D’Agostino RB, Silbershatz H, Kannel WB \& Levy D. Impact of atrial fibrillation on the risk of death. Circulation 198898 946-952.

44 Yuan Z, Bowlin S, Einstadter D, Cebul RD, Conners AR \& Rimm AA. Atrial fibrillation as a risk factor for stroke: a retrospective cohort study of hospitalized Medicare beneficiaries. American Journal of Public Health $1998 \mathbf{8 8} 395-400$.

45 Ching GW, Franklyn JA, Stallard TJ, Daykin J, Sheppard M \& Gammage MD. Cardiac hypertrophy as a result of long-term thyroxine therapy and thyrotoxicosis. Heart 199675 363-368.

46 Tseng KH, Walfish PG, Persaud JA \& Gilbert BW. Concurrent aortic and mitral valve echocardiography permits measurement of systolic time intervals as an index of peripheral tissue thyroid function status. Journal of Clinical Endocrinology and Metabolism $198969633-638$.

47 Jennings PE, O’Malley BP, Griffin KE, Northover B \& Rosenthal FD. Relevance of increased serum thyroxine concentrations associated with normal triiodothyronine values in hypothyroid patients receiving thyroxine: a case for 'tissue thyrotoxicosis'. British Medical Journal 1984289 1645-1647.

48 Banovac K, Papic M, Bisker MS, Zakarija M \& McKenzie JM. Evidence of hyperthyroidism in apparently euthyroid patients treated with levothyroxine. Archives of Internal Medicine 1989 $149809-812$.

49 Fazio S, Biondi B, Carella C, Sabatini D, Cittadini A, Panza N, Lombardi G \& Saccà L. Diastolic dysfunction in patients on thyroid-stimulating-hormone suppressive therapy with levothyroxine: beneficial effect of $\beta$ blockade. Journal of Clinical Endocrinology and Metabolism $1995802222-2226$.

50 Petretta M, Bonaduce D, Spinelli L, Vicario MLE, Nuzzo V, Marciano F, Camuso P, de Sanctis V \& Lupoli G. Cardiovascular haemodynamics and cardiac autonomic control in patients with 
subclinical and overt hyperthyroidism. European Journal of Endocrinology 2001145 691-696.

51 Klein I. Thyroxine-induced cardiac hypertrophy: time course of development and inhibition by propanolol. Endocrinology 1988 $123203-210$.

52 Rohrer D \& Dillman WH. Thyroid hormones markedly increase the mRNA coding for sarcoplasmic reticulum $\mathrm{Ca} 2+-$ ATPase in the rat heart. Journal of Biological Chemistry 1988263 6941-6944.

53 Biondi B, Fazio S, Cuocolo A, Sabatini D, Nicolai E, Lombardi G, Salvatore M \& Sacca L. Impaired cardiac reserve and exercise capacity in patients receiving long-term thyrotropin suppressive therapy with levothyroxine. Journal of Clinical Endocrinology and Metabolism $1996 \mathbf{8 1} 4224-4228$.

54 Parle JV, Maisonneuve P, Sheppard MC, Boyle P \& Franklyn JA. Prediction of all-cause and cardiovascular mortality in elderly people from one low serum thyrotropin result: a 10-year cohort study. Lancet 2001358 861-865.

55 Biondi B, Fazio S, Palmieri EA, Filetti S, Lombardi G \& Fazio S. Mortality in elderly patients with subclinical hyperthyroidism. Lancet 2002359 799-800.

56 Toh SH, Claunch BC \& Brown PH. Effect of hyperthyroidism and its treatment on bone mineral content. Archives of Internal Medicine $1985145883-886$.

57 Rosen CJ \& Adler RA. Longitudinal changes in lumbar bone density among thyrotoxic patients after attainment of euthyroidism. Journal of Clinical Endocrinology and Metabolism $1992 \quad \mathbf{7 5}$ 1531-1534.

58 Vestergaard P, Rejnmark L, Weeke J \& Mosekilde L. Fracture risk in patients treated for hyperthyroidism. Thyroid $2000 \mathbf{1 0}$ $341-348$.

59 Franklyn JA, Maisonneuve P, Sheppard MC, Betteridge J \& Boyle P. Mortality after the treatment of hyperthyroidism with radioactive iodine. New England Journal of Medicine 1998338 $712-718$.

60 Ongphiphadhanakul B, Alex S, Braverman LE \& Baran DT. Excessive L-thyroxine therapy decreases femoral bone mineral densities in the male rat: effect of hypogonadism and calcitonin. Journal of Bone and Mineral Research 19927 1227-1231.

61 Ross DS, Ardisson LJ, Nussbaum SR \& Meskell MJ. Serum osteocalcin in patients taking L-thyroxine who have subclinical hyperthyroidism. Journal of Clinical Endocrinology and Metabolism 199172 507-509.

62 Faber J, Perrild H \& Johansen JS. Bone GLA protein and sex hormone binding globulin in non-toxic goiter. Parameters for metabolic status at tissue level. Journal of Clinical Endocrinology and Metabolism $1990 \mathbf{7 0} 49-55$.

63 Harvey RD, McHardy KC, Reid IW, Paterson F, Bewsher PD, Duncan A \& Robins SP. Measurement of bone collagen degradation in hyperthyroidism and during thyroxine replacement therapy using pyridinium cross-links as specific urinary markers. Journal of Clinical Endocrinology and Metabolism 199172 $1189-1194$

64 Loviselli A, Mastinu R, Rizzolo E, Massa GM, Velluzzi F, Sammartano L, Mela Q \& Mariotti S. Circulating telopeptide type I is a peripheral marker of thyroid hormone action in hyperthyroidism and during levothyroxine suppressive therapy. Thyroid $19977561-566$

65 Kumeda Y, Inaba M, Tahara H, Kurioka Y, Ishikawa T \& Mori H. Persistent increase in bone turnover in Graves's patients with subclinical hyperthyroidism. Journal of Clinical Endocrinology and Metabolism 200085 4157-4161.

66 Ross DS, Neer RM, Ridgway EC \& Daniels GH. Subclinical hyperthyroidism and reduced bone density as a possible result of prolonged suppression of the pituitary thyroid axis with L-thyroxine. American Journal of Medicine 198782 1167-1170.

67 Paul TL, Kerrigan J, Kelly AM, Braverman LE \& Baran DT. Long-term L-thyroxine therapy is associated with decreased hip bone density in premenopausal women. Journal of the American Medical Association 1988259 3137-3141.
68 Taelman P, Kaufman JM, Janssen X, Vandecauter H \& Vermeulen A. Reduced forearm bone mineral content and biochemical evidence of increased bone turnover in women with euthyroid goiter treated with thyroid hormone. Clinical Endocrinology 199033 107-117.

69 Diamond T, Neri L \& Hales I. A therapeutic dilemma: suppressive doses of thyroxine significantly reduce bone mineral measurements in both premenopausal and postmenopausal women with thyroid carcinoma. Journal of Clinical Endocrinology and Metabolism 199072 1184-1188.

70 Lemke J, Bogner U, Felsenber D, Peters H \& Schleusener H. Determination of bone mineral density by quantitative computed tomography and single photon absorptiometry in subclinical hyperthyroidism: a risk of early osteopenia in post-menopausal women. Clinical Endocrinology 199236 511-517.

71 Schneider DL, Barrett-Connor EL \& Morton DL. Thyroid hormone use and bone mineral density in elderly women. Effects of estrogen. Journal of the American Medical Association 1994271 1245-1249.

72 Kung AW, Lorentz T \& Tam SC. Thyroxine suppressive therapy decreases bone mineral density in post-menopausal women. Clinical Endocrinology 199339 535-540.

73 Muddle AH, Houben AJ \& Nieuwenhuijzen Kruseman AC. Bone metabolism during anti-thyroid drug treatment of endogenous subclinical hyperthyroidism. Clinical Endocrinology $1994 \mathbf{4 1}$ 421-424.

74 Foldes J, Tarjan G, Szathmary M, Varga F, Krasznai I \& Horvath C. Bone mineral density in patients with endogenous subclinical hyperthyroidism: is the thyroid status a risk factor for osteoporosis? Clinical Endocrinology 199339 521-527.

75 Gurlek A \& Gedik O. Effect of endogenous subclinical hyperthyroidism on bone metabolism and bone mineral density in premenopausal women. Thyroid 19999 539-543.

76 Gorres G, Kaim A, Otte A, Gotze M \& Muller Brand J. Bone mineral density in patients receiving suppressive doses of thyroxine for differentiated thyroid carcinoma. European Journal of Nuclear Medicine 199623 690-692.

77 Marcocci C, Golia F, Vignali F \& Pinchera A. Skeletal integrity in men chronically treated with suppressive doses of L-thyroxine. Journal of Bone and Mineral Research 199712 72-77.

78 Marcocci C, Golia F, Bruno-Bossio G, Vignali E \& Pinchera A. Carefully monitored levothyroxine therapy is not associated with bone loss in premenopausal women. Journal of Clinical Endocrinology and Metabolism $1994 \mathbf{7 8} 818-823$.

79 Florkowski CM, Brownlie BE, Elliot JR, Aylin EM \& Turner JG. Bone mineral density in patients receiving suppressive doses of thyroxine for thyroid carcinoma. New Zealand Medical Journal $1993106443-444$

80 Muller CG, Bayley TA, Harrison JE \& Tsang R. Possible limited bone loss with suppressible thyroxine therapy is to have clinical relevance. Thyroid 19955 81-87.

81 Franklyn JA, Betteridge J, Daykin J, Holder R, Oates GD, Parle JV, Lilley J, Heath DA \& Sheppard MC. Long-term treatment and bone mineral density. Lancet 1992340 9-13.

82 Giannini S, Nobile M, Sartori L, Binotto P, Ciuffreda M, Gemo G, Pelizzo MR, D'Angelo A \& Crepaldi G. Bone density and mineral metabolism in thyroidectomized patients treated with long-term thyroxine. Clinical Science 199487 593-597.

83 Garton M, Reid I, Loveridge N, Robins S, Murchison L, Beckett G \& Reid D. Bone mineral density and metabolism in premenopausal women taking L-thyroxine replacement therapy. Clinical Endocrinology 199441 747-755.

84 De Rosa G, Testa A, Maussier ML, Calla C, Astazi P \& Albanese C. A slight suppressive dose of L-thyroxine does not affect bone turnover and bone mineral density in pre- and postmenopausal women with non-toxic goiter. Hormone and Metabolic Research 199527 503-507.

85 Nuzzo V, Lupoli G, del Puente E, Rampone E, Carpinelli A, del Puente $\mathrm{AE} \&$ Oriente $\mathrm{P}$. Bone mineral density in 
premenopausal women receiving levothyroxine suppressive therapy. Gynecological Endocrinology 199812 333-337.

86 Saggese G, Bertelloni S, Baroncelli GI, Costa S \& Ceccarelli C. Bone mineral density in adolescent females treated with L-thyroxine; a longitudinal study. European Journal of Pediatrics 1996 155 452-457.

87 Adlin EV, Maurer AH, Marks AD \& Channick BJ. Bone mineral density in postmenopausal women treated with L-thyroxine. American Journal of Medicine 199190 360-366.

88 Grant DJ, McMurdo ME, Mole PA, Paterson CR \& Davies RR. Suppressed TSH secondary to thyroxine therapy are not associated with osteoporosis. Clinical Endocrinology $199339529-533$.

89 Ribot C, Tremollieres F, Pouilles JM \& Louvet JP. Bone mineral density and thyroid hormone therapy. Clinical Endocrinology $199033143-153$.

90 Hawkins F, Rigopoulou D, Papapietro K \& Lopez MB. Spinal bone mass after long term treatment with L-thyroxine in postmenopausal women with thyroid cancer and chronic lymphocytic thyroiditis. Calcified Tissue International 1994 54 16-19.

91 Bauer DC, Newitt MC, Ettinger B \& Stone K. Low thyrotropin levels are not associated with bone loss in older women: a prospective study. Journal of Clinical Endocrinology and Metabolism $1977822931-2936$.

92 Pioli G, Pedrazzoni M, Palummeri E, Sianesi M, del Frate R, Vescovi PP, Prisco M, Ulietti V, Costi D \& Passeri M. Longitudinal study of bone loss after thyroidectomy and suppressive thyroxine therapy in premenopausal women. Acta Endocrinologica 1992 $126238-242$.

93 McDermott MT, Perloff JJ \& Kidd GS. A longitudinal assessment of bone loss in women with levothyroxine-suppressed benign thyroid disease and thyroid cancer. Calcified Tissue International $199556521-525$.

94 Rosen HN, Moses AC, Garber J, Ross DS, Lee SL, Ferguson L, Chen V, Lee K \& Greenspan SL. Randomized trial of pamidronate in patients with thyroid cancer: bone density is not reduced by suppressive doses of thyroxine, but is increased by cyclic intravenous pamidronate. Journal of Clinical Endocrinology and Metabolism $1998832324-2330$.

95 Guo CY, Weetman AP \& Eastell R. Longitudinal changes of bone mineral density and bone turnover in postmenopausal women on thyroxine. Clinical Endocrinology 199746 301-307.

96 Uzzan B, Campos J, Cucherat M, Nony P, Boissel JP \& Perret GY. Effects on bone mass of long-term treatment with thyroid hormones: a meta-analysis. Journal of Clinical Endocrinology and Metabolism $1996 \mathbf{8 1} 4278-4289$.

97 Faber J \& Galloe AM. Changes in bone mass during prolonged subclinical hyperthyroidism due to L-thyroxine treatment: a meta-analysis. European Journal of Endocrinology 1994130 350-356.

98 Foldes J, Lakatos P, Zsadanyi J \& Horvath C. Decreased serum IGF-I and dehydroepiandrosterone sulphate may be risk factors for the development of reduced bone mass in postmenopausal women with endogenous subclinical hyperthyroidism. European Journal of Endocrinology 1997136 277-281.

99 Franklyn J, Betteridge J, Holder R, Daykin J, Lilley J \& Sheppard $\mathrm{M}$. Bone mineral density in thyroxine treated females with or without a previous history of thyrotoxicosis. Clinical Endocrinology $1994 \mathbf{4 1} 425-432$.

100 Grant DJ, McMurdo ET, Mole PA \& Peterson CR. Is previous hyperthyroidism still a risk factor for ostoporosis in post-menopausal women? Clinical Endocrinology 199543 339-345.
101 Solomon BL, Wartofsky L \& Burman KD. Prevalence of fractures in postmenopausal women with thyroid disease. Thyroid 19933 $17-23$.

102 Leese GP, Jung RT, Guthrie C, Waugh N \& Browning MC. Morbidity in patients on L-thyroxine: a comparison of those with a normal TSH to those with a suppressed TSH. Clinical Endocrinology 199237 500-503.

103 Sheppard MC, Holder R \& Franklyn JA. Levothyroxine treatment and occurrence of fracture of the hip. Archives of Internal Medicine $2002162338-343$.

104 Bauer DC, Ettinger B, Nevitt MC \& Stone KL, for the Study of Osteoporotic Fractures. Risk for fracture in women with low serum levels of thyroid-stimulating hormone. Annals of Internal Medicine 2001134 561-568.

105 Forfar JC, Feek CM, Miller HC \& Toft AD. Atrial fibrillation and isolated suppression of the pituitary thyroid axis. Response to specific antithyroid therapy. International Journal of Cardiology $1981143-48$.

106 Faber J, Wiinberg N, Schifter S \& Mehlsen J. Hemodynamic changes following treatment of subclinical and overt hyperthyroidism. European Journal of Endocrinology 2001145 391-396.

107 Forfar JC, Miller H \& Toft A. Occult thyrotoxicosis: a correctable cause of 'idiopathic' atrial fibrillation. American Journal of Cardiology $1979 \mathbf{4 4} 9-12$.

108 Chiacchieri M, Cecchi F, Arcangeli C, Dolara A, Zuppiroli A \& Pieroni C. Occult thyrotoxicosis in patients with chronic and paroxysmal isolated atrial fibrillation. Clinical Cardiology 1984 7 413-416.

109 Faber J, Jensen IW, Petersen L, Nygaard B, Hegedus L \& Siersbaek-Nielsen K. Normalization of serum thyrotropin by mean of radioiodine treatment in subclinical hyperthyroidism. Effect of bone loss in postmenopausal women. Clinical Endocrinology $199848285-290$.

110 Kung AW \& Yeung SS. Prevention of bone loss induced by thyroxine suppressive therapy in postmenopausal women: the effect of calcium and calcitonin. Journal of Clinical Endocrinology and Metabolism 199681 1232-1236.

111 Rosen HN, Moses AC, Gundberg C, Kung VT, Seyedin SM, Chen T, Holick M \& Greenspan SL. Therapy with parenteral pamidronate prevents thyroid hormone bone turnover in humans. Journal of Clinical Endocrinology and Metabolism 199377 664-669.

112 Rosen HN, Moses A, Garber J, Garber J, Ross DS, Lee SL, Ferguson L, Chen V, Lee K \& Greenspan SL. Randomized trial of pamidronate in patients with thyroid cancer. Bone density is not reduced by suppressive doses of thyroxine, but is increased by cyclic intravenous pamidronate. Journal of Clinical Endocrinology and Metabolism $1998 \mathbf{8 3} 2324-2330$.

113 Biondi B, Palmieri EA, Lombardi G \& Fazio S. Effects of subclinical thyroid dysfunction on the heart. Annals of Internal Medicine $2002137904-914$.

114 Thomas FB, Mazzaferri EL \& Skillman TG. Apathetic thyrotoxicosis: a distinct clinical and laboratory entity. Annals of Internal Medicine 197072 679-685.

115 Sawin CT. Subclinical hyperthyroidism and atrial fibrillation. Thyroid $200212501-503$.

Received 14 May 2004

Accepted 23 September 2004 